\title{
Case Report \\ Eikenella Corrodens, Cause of a Vulvar Abscess in a Diabetic Adult
}

\author{
Nefise Öztoprak, ${ }^{1}$ Ülkü Bayar, ${ }^{2}$ Güven Çelebi, ${ }^{1}$ Mustafa Basaran, ${ }^{2}$ and Füsun Cömert ${ }^{3}$ \\ ${ }^{1}$ Department of Infectious Diseases and Clinical Microbiology, Faculty of Medicine, Zonguldak Karaelmas University, \\ 67600 Zonguldak, Turkey \\ ${ }^{2}$ Department of Obstetrics and Gynecology, Faculty of Medicine, Zonguldak Karaelmas University, 67600 Zonguldak, Turkey \\ ${ }^{3}$ Department of Microbiology and Clinical Microbiology, Faculty of Medicine, Zonguldak Karaelmas University, \\ 67600 Zonguldak, Turkey
}

Received 1 September 2006; Revised 12 October 2006; Accepted 20 October 2006

\begin{abstract}
We report a case of Eikenella corrodens causing vulvar abscess in a diabetic patient. Eikenella corrodens is a slow growing, nonmotile, facultative anaerobic, Gram-negative bacillus which is commensal of the oral cavity, intestinal and genital tracts. The most common clinical sources of this organism are human bite wounds, head and neck infections and respiratory tract infections. In our knowledge, the presented case is the first report of Eikenella corrodens causing vulvar abscess in a diabetic patient.
\end{abstract}

Copyright (c) 2007 Nefise Öztoprak et al. This is an open access article distributed under the Creative Commons Attribution License, which permits unrestricted use, distribution, and reproduction in any medium, provided the original work is properly cited.

\section{INTRODUCTION}

Eikenella corrodens is a slow growing, nonmotile, facultative anaerobic, Gram-negative bacillus which is commensal of the oral cavity, intestinal and genital tracts [1-3]. The most common clinical sources of this organism are human bite wounds, head and neck infections and respiratory tract infections $[1,2,4]$. Eikenella species have also been shown to cause endocarditis, intraabdominal infection, pancreatic abscess, arthritis, vertebral osteomyelitis, discitis, orbital cellulites, thyroid abscess, brain abscess, liver abscess and genitourinary infections $[1-3,5-8]$. According to our research, this is the first report of Eikenella corrodens causing vulvar abscess in a diabetic patient in English literature.

\section{CASE}

A diabetic 55 year old woman was admitted to Zonguldak Karaelmas University emergency clinic with a complain of an insidious onset of swelling in the left part of vulva, a pain radiating to the left inguinal region, chills and high fever over a week. She has had hypertension and type II diabetes mellitus and has used oral anti-diabetic and anti-hypertension drugs for 8 years. She had no history of previous trauma, operation, underlying skin lesion, use of foreign body or human bite on her vulvar region. Two days after onset, her left part of the vulva became swelling and the lesions color turned to red.
Even though she had used amoxicilline-clavulanic acid and ornidasole for three days, the lesion on the vulva and pain worsened.

In clinical examination her fever $38^{\circ} \mathrm{C}$, pulse $96 / \mathrm{dk}$, blood pressure $160 / 80 \mathrm{mmHg}$, in the left part of the vulva there was an erode lesion in the certain part of the inflammatory halo. The lesion was $5 \times 4 \mathrm{~cm}$ in size, red, hot, swollen, and painful and fluctuant. Local tenderness and edema were also marked (Figure 1). The borders of the lesion was not elevated and sharply demarcated.

Laboratory values were as follows: WBC count, $18200 / \mathrm{mm}^{3}$ (82\% neutrophils, $8 \%$ lymphocyte, $8 \%$ monocytes) $\left[4000-10000 / \mathrm{mm}^{3}\right]$; erythrocyte sedimentation rate (ESR), $122 \mathrm{~mm} /$ hour [0-20 mm/hour]; C-reactive protein, $(++++)$ [negatif]; and blood glucose, $235 \mathrm{mg} / \mathrm{dL}$ [70-110 $\mathrm{mg} / \mathrm{dL}]$.

Vulvar abscess was diagnosed and it was drained. In Gram stain of the pus, granulocytes (80\% neutrophil), Gram-negative rods and Gram-positive cocci were detected. Ampicilline-sulbactam $4 \times 1$ gr IV/day, ciprofloxacin $2 \times$ $400 \mathrm{mg}$ IV/day and local care with $2 \%$ eau borique fluid were started empirically. Her oral anti-diabetic drugs stopped and IV insulin treatment started. The blood glucose was in regular limits after IV insulin treatment began. Following drainage, her fever, leucocyt count became normal and, edema, pain and erythema of the lesion subsided. 


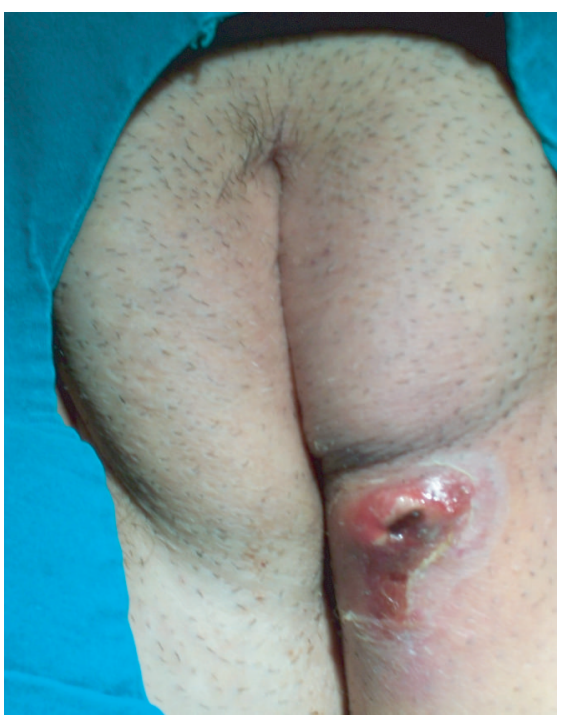

Figure 1: Vulvar abscess (The lesion is $5 \times 4 \mathrm{~cm}$ in size, red, and swollen).

Eikenella corrodens and metisilline sensitive Staphylococcus epidermidis (MSSE) were isolated from culture of the pus. After 3 days of the treatment her fever, white blood cell count was normal, ESR was $100 \mathrm{~mm} /$ hour. The patient completed 14 days of treatment with resolution of signs and symptoms. The ESR was $72 \mathrm{~mm} /$ hour in the first week of the treatment, $30 \mathrm{~mm} /$ hour at the end of the treatment. An informed consent was obtained from the patient to use of her photographs.

\section{DISCUSSION}

Eikenella corrodens is commonly found in oral, gastrointestinal, and genitourinary flora. A break in barriers, such as mucous membranes or the skin, can lead to hematogenous spread and serious Eikenella infections [2]. It is described that previous or concomitant illness had a greater association with Eikenella infections than did a previously healthy status [2]. Diabetes mellitus is one of these underlying conditions; our case is also type II diabetic patient.

Eikenella is typically susceptible to many antibiotics, including penicillin $\mathrm{G}$, ceftriaxone, amoxicillin-clavulonic acid, and fluoroquinolones [2]. Some of the $\beta$-laktamases produced by Eikenella are inhibited by clavulonate and sulbactam, however $\beta$-laktamase production is uncommon at present [1]. Surgical drainage may be more important than antibiotics alone in the management of Eikenella infections [2]. Our patient was started on amoxicillin-clavulonate and ornidasole before admitting to our hospital and not responded well until drainage of the abscess. Depending on the location of infection, treatment choice is a combination of surgical management and antibiotics. Our patient has been successfully treated with ampicilline-sulbactam and ciprofloxacin for 14 days.

There are a few literatures reporting that ESR is a valuable test in genital abscess $[9,10]$. However, we could not find any study showing correlation between ESR level and vulvar abscess. On the other hand, in a study reported by Paul and Patel including 54 children and adolescents with E. corrodens infections elevated ESR was detected for most of the patients and the authors considered that ESR was a better indicator than WBC count for E. corrodens infections [2]. In this case, ESR was $122 \mathrm{~mm} /$ hour at the onset of the illness and ESR level reduced to $30 \mathrm{~mm} /$ hour at the end of the treatment.

E. corrodens causes various clinical manifestations especially in diabetic patients and ESR may be a good indicator of Eikenella corrodens infections.

\section{REFERENCES}

[1] J S Steinberg and C D Rio, "Other Gram-negative and Gramvariable bacilli," in Principles and Practice of Infectious Diseases, G L Mandell, J E Bennett, and R Dolin, Eds., pp. 2031-2038, Churchill Livingstone, New York, NY, 6th edition, 2005.

[2] K Paul and S S Patel, "Eikenella corrodens infections in children and adolescents: case reports and review of the literature," Clinical Infectious Diseases, vol. 33, no. 1, pp. 54-61, 2001.

[3] M K Sayana, A J Chacko, and R C Mc Givney, "Unusual cause of infective discitis in an adolescent," Postgraduate Medical Journal, vol. 79, no. 930, pp. 237-238, 2003.

[4] K-S Wong and Y-C Huang, "Bronchopleural cutaneous fistula due to Eikenella corrodens," Jornal de Pediatria, vol. 81, no. 3, pp. 265-267, 2005.

[5] A T Kessler and A P Kourtis, "Liver abscess due to Eikenella corrodens from a fishbone," New England Journal of Medicine, vol. 345 , no. 23 , p. e5, 2001.

[6] R Karunakaran, M J Marret, H Hassan, and S D Puthucheary, "Eikenella corrodens from a brain abscess," The Malaysian Journal of Pathology, vol. 26, no. 1, pp. 49-52, 2004.

[7] E Drouet, H De Montclos, M Boude, and G A Denoyel, "Eikenella corrodens and intrauterine contraceptive device," The Lancet, vol. 330, no. 8567, p. 1089, 1987.

[8] K G Jeppson and L G Reimer, "Eikenella corrodens chorioamnionitis," Obstetrics and Gynecology, vol. 78, no. 3 pt 2, pp. 503-505, 1991.

[9] A Petrucca, P Cipriani, R Sessa, et al., "Burkholderia cenocepacia vaginal infection in patient with smoldering myeloma and chronic hepatitis C," Emerging Infectious Diseases, vol. 10, no. 11, pp. 1957-1959, 2004.

[10] D Charles, "Value of the erythrocyte sedimentation rate in gynecologic infections," Clinical Obstetrics and Gynecology, vol. 19, no. 1, pp. 171-193, 1976. 


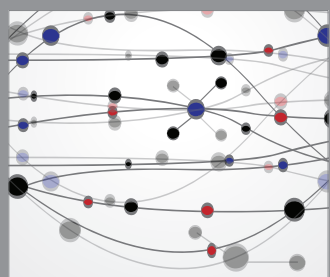

The Scientific World Journal
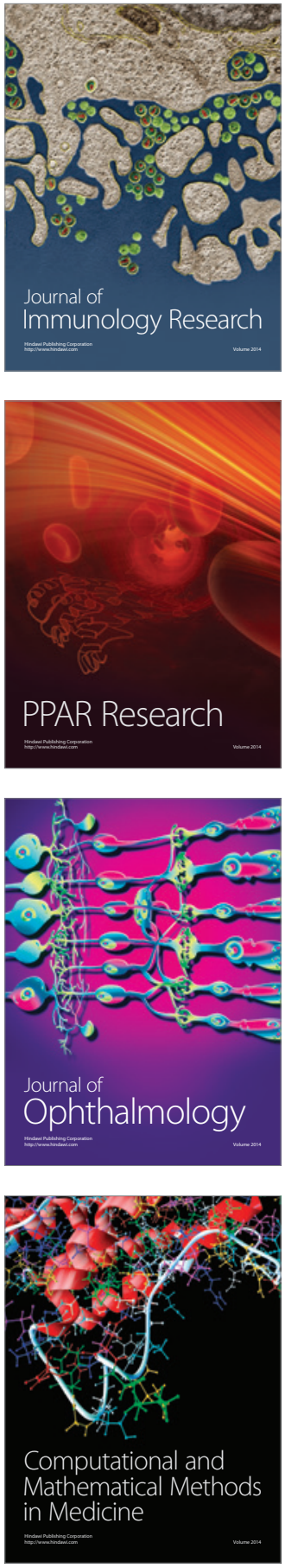

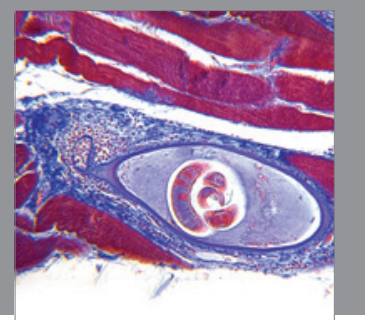

Gastroenterology

Research and Practice
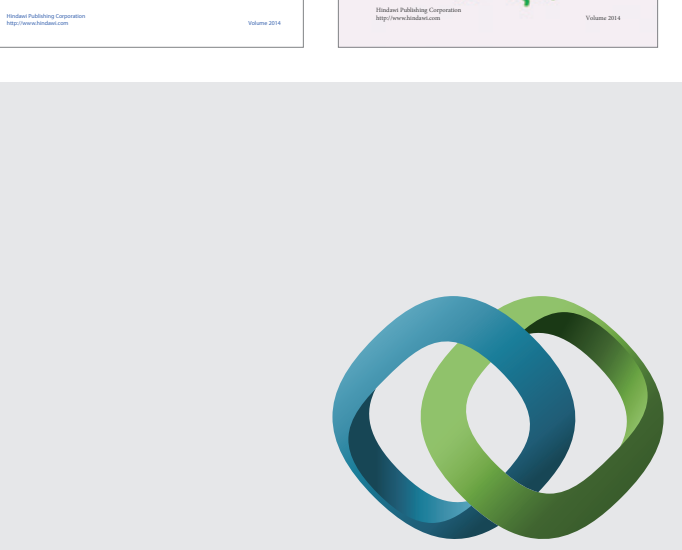

\section{Hindawi}

Submit your manuscripts at

http://www.hindawi.com
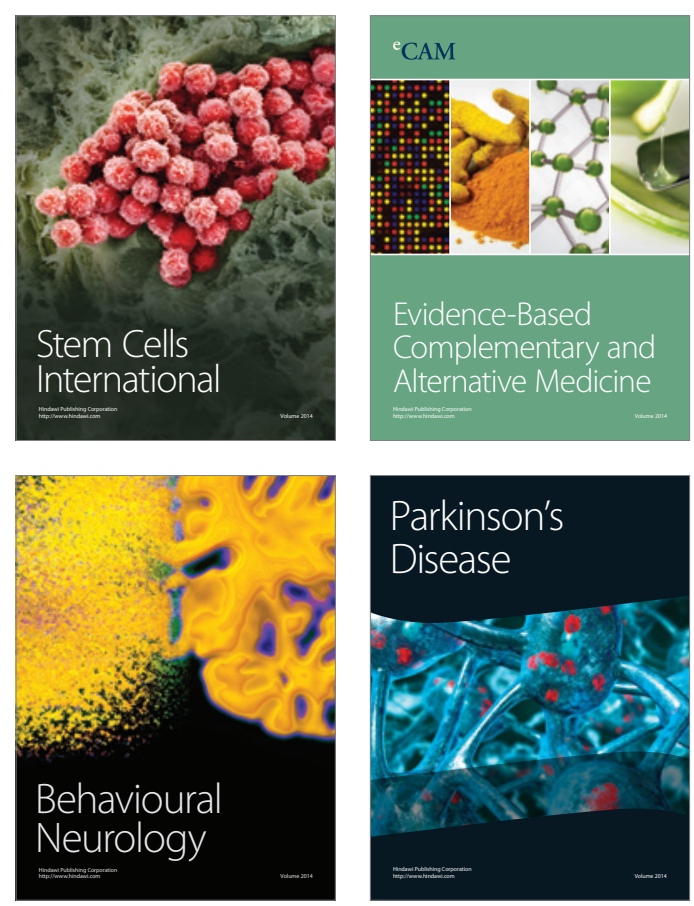

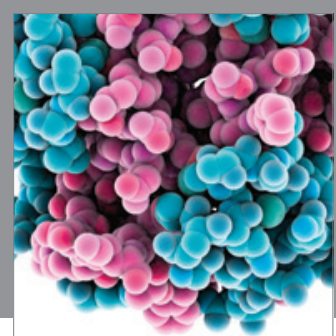

Journal of
Diabetes Research

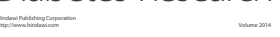

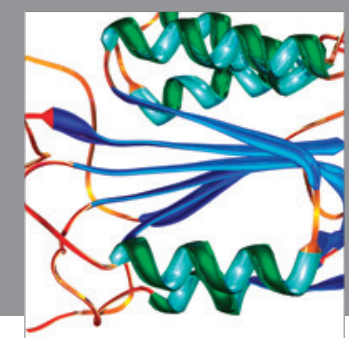

Disease Markers
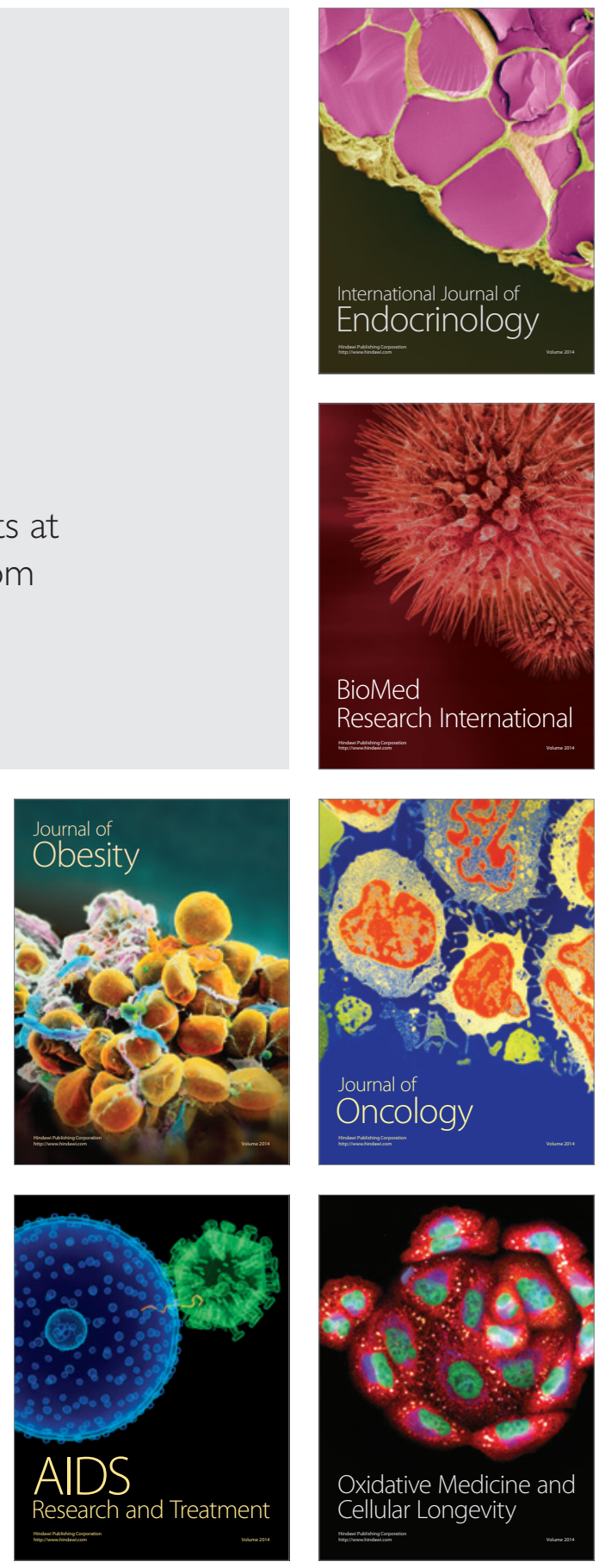